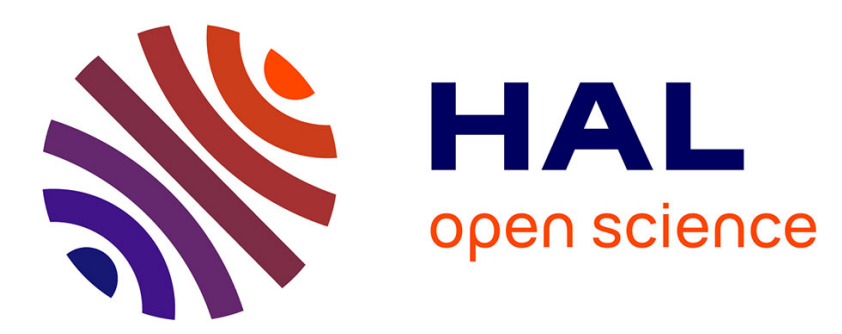

\title{
Are metabolically healthy obese patients also hemorheologically healthy?
}

Jean-Frédéric Brun, Emmanuelle Varlet-Marie, Christine Fedou, E. Raynaud

\section{To cite this version:}

Jean-Frédéric Brun, Emmanuelle Varlet-Marie, Christine Fedou, E. Raynaud. Are metabolically healthy obese patients also hemorheologically healthy? Clinical Hemorheology and Microcirculation, 2015, 61 (1), pp.39 - 46. 10.3233/CH-141868 . hal-01756270

\section{HAL Id: hal-01756270 \\ https://hal.umontpellier.fr/hal-01756270}

Submitted on 30 Jan 2020

HAL is a multi-disciplinary open access archive for the deposit and dissemination of scientific research documents, whether they are published or not. The documents may come from teaching and research institutions in France or abroad, or from public or private research centers.
L'archive ouverte pluridisciplinaire $\mathbf{H A L}$, est destinée au dépôt et à la diffusion de documents scientifiques de niveau recherche, publiés ou non, émanant des établissements d'enseignement et de recherche français ou étrangers, des laboratoires publics ou privés. 


\title{
Are metabolically healthy obese patients also hemorheologically healthy?
}

\author{
Jean-Frédéric Brun ${ }^{\mathrm{a}, *}$, Emmanuelle Varlet-Marie ${ }^{\mathrm{b}, \mathrm{c}}$, Christine Fedou ${ }^{\mathrm{a}}$ \\ and Eric Raynaud de Mauverger ${ }^{a}$
}

"INSERM U1046 "Physiopathologie \& Médecine Expérimentale du Cœur et des Muscles", Equipe d'Explorations Métaboliques (CERAMM), Université Montpellier 1, Université Montpellier 2, Département de Physiologie Clinique, Hôpital Lapeyronie CHU Montpellier, France ${ }^{\mathrm{b}}$ Institut des Biomolécules Max Mousseron (IBMM) UMR CNRS 5247, Université Montpellier 1, Université Montpellier 2, Ecole Nationale Supérieure de Chimie de Montpellier, France ${ }^{\mathrm{c}}$ Laboratoire de Biophysique \& Bio-Analyses, Faculté de Pharmacie, Université Montpellier 1, France

\begin{abstract}
We examined whether "metabolically healthy obesity" (MHO) is associated or not with hemorheologic alterations. We studied 110 subjects: 32 normal weight; 40 overweight; 38 obese. Overweight and obese subjects were divided into two subgroups according to the occurrence or not of a metabolic syndrome (METS). Subjects were thus categorized as follows: (1) metabolically healthy and normal weight (MHNW); (2) metabolically healthy but overweight (MHOW); (3) metabolically abnormally overweight (MAOW); (4) metabolically healthy but obese (MHOB); and (5) metabolically abnormally obese (MAOB). Across those various subgroups whole blood viscosity and plasma viscosity were not statistically different, although there was a tendency to higher values in the subgroups with METS compared to those without METS. RBC aggregation "M" was higher in all obese than MHNW (7.25 \pm 0.64 vs $4.31 \pm 0.44 p<0.001$ and was also higher in MHOB than MHNW (8.22 $\pm 1.07 v s$ $4.31 \pm 0.44 v s 8.22 \pm 1.07 p<0.02)$. It was higher in all obese subjects than in all overweight subjects $(7.25 \pm 0.64 v s 5.22 \pm 0.40$ $p<0.01$ ) but the difference between overweight and MHNW was not significant. M was negatively correlated with insulin sensitivity $(r=-0.457 p=0.0008)$. On the whole increased RBC aggregability "M" seems to be more related to fatness by its own than to the occurrence of metabolic abnormalities. MHO is not associated with alterations of blood viscosity at high shear rate, but exhibits a slight increase in RBC aggregability. These data are consistent with the assumption that MHO is on the whole a "hemorheologically healthy" situation, but that RBC aggregability is proportional to fatness even in "healthy" conditions, as already observed in samples of normal weight athletes.
\end{abstract}

Keywords: Obesity, hemorheology, erythrocyte aggregation, insulin sensitivity

\section{List of symbols}

METS: metabolic syndrome

MHO: metabolically healthy obesity

MHNW: metabolically healthy and normal weight

MHOW: metabolically healthy but overweight

*Corresponding author: Jean-Frédéric Brun, INSERM U1046 "Physiopathologie \& Médecine Expérimentale du Cœur et des Muscles”, Equipe d'Explorations Métaboliques (CERAMM), Université Montpellier 1, Université Montpellier 2, Département de Physiologie Clinique, Hôpital Lapeyronie CHU Montpellier, France. E-mail: j-brun@chu-montpellier.fr. 
MAOW: metabolically abnormally overweight

MHOB: metabolically healthy but obese

MAOB: metabolically abnormally obese

RBC: red blood cell

SEM: $\quad$ standard error on the mean

\section{Introduction}

Obesity is associated with an increased risk of comorbidities such as non-alcoholic fatty liver disease, hypertension, type 2 diabetes mellitus (DM), coronary artery disease (CAD), stroke, and several cancers, but there is a significant proportion of subjects with obesity who do not develop dysmetabolic status [17]. These individuals, now defined as metabolically healthy but obese (MHO), despite having excessive body fat, display a favorable metabolic profile characterized by high levels of insulin sensitivity, no hypertension, a favorable immune profile, normal lipid, low inflammation, and beneficial hormonal profiles [11].

Evidence has been reported that these MHO individuals may account for as much as $20 \%-50 \%$ of the obese population [6]. This phenotype has been reported to be associated with a less deleterious cardiovascular prognosis [13]. Obesity is generally associated with a moderate hyperviscosity syndrome, related to metabolic and inflammatory abnormalities $[1,12,19]$.

To our knowledge, whether MHO is associated or not with hemorheologic alterations remains unclear. Le Devehat [12] in his paper which was one of the very first devoted to hemorheology and obesity evidenced a host of hemorheologic alterations in "isolated obesity", a situation which is actually quite similar to that nowadays termed MHO. However, definitions of 'isolated obesity' according to this author and $\mathrm{MHO}$ are not exactly similar, so that it was logic to address this question with the current definitions. This was the aim of this study designed to compare blood rheology between MHO and dysmetabolic obesity.

\section{Experimental}

\subsection{Subjects}

We studied 110 subjects: 32 normal weight (age: 14-60 years); 40 overweight (BMI 25-30; age: 11-68 yr); 38 obese (BMI $>30-67.5$, age: 11-77). Overweight and obese subjects were splitted in two subgroups according to the occurrence or not of a metabolic syndrome (METS). Subjects were thus categorized as follows: (1) metabolically healthy and normal weight (MHNW); (2) metabolically healthy but overweight (MHOW); (3) metabolically abnormally overweight (MAOW); (4) metabolically healthy but obese (MHOB); and (4) metabolically abnormally obese (MAOB).

\subsection{Bioelectrical impedance measurements}

Prior to the exercise-test, subjects' body composition was assessed with bioimpedance analysis with a six terminal impedance plethismograph BIACORPUS RX 4000 Biacorpus RX4000, (Healthnesslink, 8 avenue Jean-Jaurès 92130 Issy-les-Moulineaux, France) with data analysis with the softwareBodyComp 8.4. This device measures total resistance of the body to an alternative electric current of $50 \mathrm{kHz}$ [2]. Body 
fat mass, fat-free mass were calculated in each segment of the body according to manufacturer's databasederived disclosed equations, and total water with published equations using the classical cylindric model and Hanai's mixture theory [7].

\subsection{Hemorheological ex vivo measurements}

Blood samples for hemorheological measurements $(7 \mathrm{ml})$ were drawn with potassium EDTA as the anticoagulant in a vacuum tube (Vacutainer). Viscometric measurements were done at very high shear rate $\left(1000 \mathrm{~s}^{-1}\right)$ with a falling ball viscometer (MT 90 Medicatest, F-86280 Saint Benoit) [4]. The coefficient of variation of this method ranges between 0.6 and $0.8 \%$. We measured with this device apparent viscosity of whole blood at native hematocrit, plasma viscosity, and blood viscosity at corrected hematocrit (45\%) according to the equation of Quemada [14].

$$
\eta=\eta_{p}(1-1 / 2 k \phi)^{-2}
$$

where $\phi$ is hematocrit, $\eta_{p}$ is plasma viscosity, and $\mathrm{k}(\gamma)$ is a shear-dependent parameter quantifying the contribution of erythrocyte rheological properties to whole blood viscosity.

At the high shear rate used here $\mathrm{k}(\gamma)$ is representative of red cell rigidity (i.e., the lower $\mathrm{k}(\gamma)$, the higher is erythrocyte deformability).

With this equation it is possible to standardize $\eta$ for hematocrit $45 \%$ after calculating $k$ :

$$
k=2 .\left(1-\eta r^{-0.5}\right) \cdot \phi^{-1}
$$

This value of $\mathrm{k}$ is reintroduced in equation (1) with $\phi$ set at 0.45 . Dintenfass's 'Tk' index [3] was also calculated as an index of red cell rigidity.

RBC aggregation was assessed with the Myrenne aggregometer [16] which gives two indices of RBC aggregation: 'M' (aggregation during stasis after shearing at $600 \mathrm{~s}^{-1}$ ) and 'M1' (facilitated aggregation at low shear rate after shearing at $600 \mathrm{~s}^{-1}$ ). It was also measured with laser backscattering (erythroagregometer SEFAM - AFFIBIO) [5]. Hematocrit was measured with microcentrifuge.

\subsection{Statistics}

Values are presented as mean \pm standard error of the mean (SEM). Normality of samples was checked with the Kolmogorov-Smirnov test. After verification of normality, we used a one way ANOVA followed by a Student's $t$ test for unpaired samples. Correlations were assessed with Pearson's procedure (least square fitting). A value of $p<0.05$ was considered as significant.

\section{Results}

\subsection{Baseline characteristics of subjects}

This study included 32 normal weight (age: 14-60 years); 40 overweight (BMI 25-30; age: 11-68 yr) and 38 obese subjects (BMI $>30-67.5$, age: $11-77$ ). They were classified into five groups: (1) metabolically healthy and normal weight (MHNW); (2) metabolically healthy but overweight (MHOW); (3) metabolically abnormally overweight (MAOW); (4) metabolically healthy but obese (MHOB); and (5) metabolically abnormally obese (MAOB). Characteristics of these subgroups are shown on Table 1. 
Table 1

Age, weight, height and body mass index (BMI) of the subjects of the study

\begin{tabular}{|c|c|c|c|c|c|c|}
\hline & Age & Weight & Height & BMI & Total cholesterol (g/l) & Triglycerides ( $g / l)$ \\
\hline $\begin{array}{l}\text { MHNW } \\
n=32\end{array}$ & $29.75 \pm 2.04$ & $66.84 \pm 1.81$ & $1.70 \pm 0.02$ & $22.99 \pm 0.25$ & $2.10 \pm 0.12$ & $0.79 \pm 0.08$ \\
\hline $\begin{array}{l}\text { MHOW } \\
n=30\end{array}$ & $35.77 \pm 2.46$ & $73.52 \pm 1.72$ & $1.65 \pm 0.02$ & $26.91 \pm 0.24$ & $2.17 \pm 0.09$ & $0.92 \pm 0.09$ \\
\hline $\begin{array}{l}\text { MAOW } \\
n=10\end{array}$ & $48.30 \pm 4.47$ & $79.45 \pm 3.81$ & $1.70 \pm 0.04$ & $27.48 \pm 0.55$ & $2.24 \pm 0.10$ & $1.09 \pm 0.26$ \\
\hline $\begin{array}{l}\text { MHOB } \\
n=16\end{array}$ & $43.84 \pm 5.00$ & $89.05 \pm 5.40$ & $1.60 \pm 0.02$ & $34.81 \pm 2.39$ & $2.44 \pm 0.11$ & $1.19 \pm 0.09$ \\
\hline $\begin{array}{l}\text { MAOB } \\
n=22\end{array}$ & $46.64 \pm 2.63$ & $103.01 \pm 3.84$ & $1.68 \pm 0.02$ & $36.83 \pm 1.26$ & $2.32 \pm 0.11$ & $2.20 \pm 0.42$ \\
\hline
\end{tabular}

\subsection{Hemorheological parameters}

As shown on Table 2, across those various subgroups whole blood viscosity and plasma viscosity were not statistically different, although there was a tendency to higher values in the subgroups with METS compared to those without METS. As shown on Fig. 1, RBC aggregation ' $M$ ' was higher in all obese than MHNW ( $7.25 \pm 0.64 v s 4.31 \pm 0.44 p<0.001$ and was also higher in MHOB than MHNW (8.22 $\pm 1.07 v s$ $4.31 \pm 0.44$ vs $8.22 \pm 1.07 p<0,02)$. It was higher in all obese subjects than in all overweight subjects (7.25 \pm 0.64 vs $5.22 \pm 0.40 p<0.01$ ) but the difference between overweight and MHNW was not significant.

\subsection{Correlations among study parameters}

Table 3 shows correlations among various parameters. ' $M$ ' was negatively correlated with insulin sensitivity $(r=-0.457 p=0.0008)$. There were also correlations between the body mass index and both

Table 2

Hemorheological parameters across the various categories of body weight

\begin{tabular}{|c|c|c|c|c|c|c|c|}
\hline & $\begin{array}{c}\text { Whole blood } \\
\text { viscosity at } \\
\text { native hematocrit } \\
\text { (mPa.s) }\end{array}$ & $\begin{array}{c}\text { Plasma } \\
\text { viscosity } \\
\text { (mPa.s) }\end{array}$ & $\begin{array}{c}\mathrm{RBC} \\
\text { viscometric } \\
\text { index of } \\
\text { rigidity ' } \mathrm{Tk} \text { ' }\end{array}$ & $\begin{array}{c}\text { RBC } \\
\text { aggregability } \\
\text { Myrenne } \\
\text { index 'M' }\end{array}$ & $\begin{array}{c}\text { RBC } \\
\text { aggregability } \\
\text { Myrenne } \\
\text { index 'M1' }\end{array}$ & $\begin{array}{l}\text { Whole blood } \\
\text { viscosity at } \\
\text { hematocrit } \\
45 \% \text { (mPa.s) }\end{array}$ & $\begin{array}{l}\text { Hematocrit/ } \\
\text { viscosity ratio }\end{array}$ \\
\hline $\begin{array}{l}\text { MHNW } \\
n=32\end{array}$ & $2.64 \pm 0.07$ & $37 \pm 0.01$ & $0.54 \pm 0.02$ & $4.31 \pm 0.44$ & $7.03 \pm 0.40$ & $2.81 \pm 0.10$ & $16.19 \pm 0.37$ \\
\hline $\begin{array}{l}\text { MHOW } \\
n=30\end{array}$ & $2.63 \pm 0.06$ & $1.36 \pm 0.01$ & $0.56 \pm 0.01$ & $5.11 \pm 0.51$ & $7.94 \pm 0.62$ & $2.81 \pm 0.06$ & $15.68 \pm 0.27$ \\
\hline $\begin{array}{l}\text { MAOW } \\
n=10\end{array}$ & $2.67 \pm 0.09$ & $1.34 \pm 0.03$ & $0.57 \pm 0.02$ & $5.50 \pm 0.59$ & $9.28 \pm 0.61$ & $2.82 \pm 0.09$ & $15.95 \pm 0.57$ \\
\hline $\begin{array}{l}\text { МHOB } \\
n=16\end{array}$ & $2.54 \pm 0.05$ & $1.36 \pm 0.02$ & $0.53 \pm 0.02$ & $8.23 \pm 1.07$ & $12.70 \pm 1.00$ & $2.71 \pm 0.06$ & $16.26 \pm 0.32$ \\
\hline $\begin{array}{l}\text { MAOB } \\
n=22\end{array}$ & $2.67 \pm 0.07$ & $1.35 \pm 0.02$ & $0.56 \pm 0.01$ & $7.03 \pm 0.74$ & $11.29 \pm 0.70$ & $2.74 \pm 0.10$ & $15.89 \pm 0.40$ \\
\hline
\end{tabular}



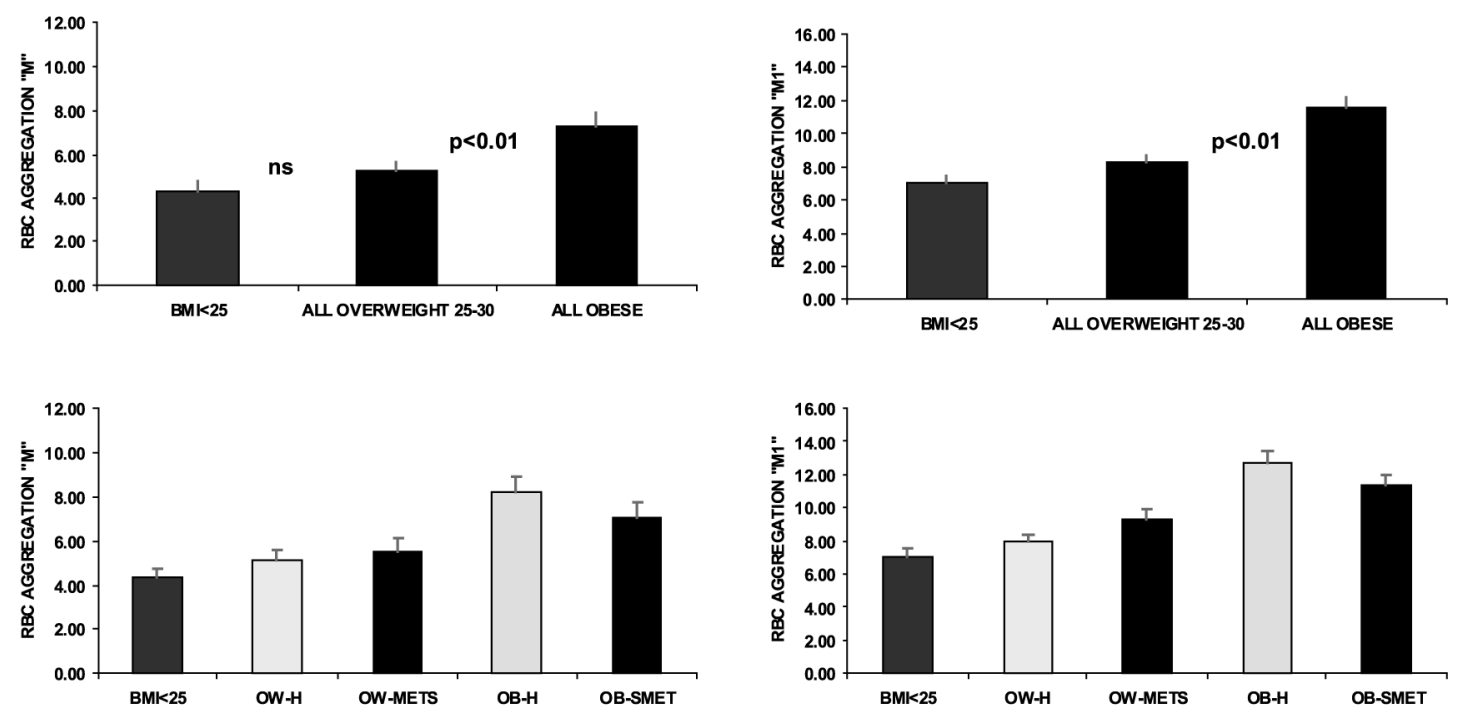

Fig. 1. RBC aggregation mesasured by the Myrenne aggregometer was increased by obesity itself regardless it was metabolically healthy or unhealthy, and was not increased in simple overweight.

'M' $(r=0.542 P=0.00005)$ and 'M1' $(r=0.652 p=0.0000004)$. Insulin sensitivity also displayed its previously reported correlations with blood viscosity, RBC aggregability and RBC rigidity.

\section{Discussion}

To the best of our knowledge, the present study is the first to investigate hemoheology in MHO. Our results evidence a moderate increase in RBC aggregability that seems to be more related to fatness by its own than to the occurrence of metabolic abnormalities. By contrast, MHO does not seem to be associated with alterations of blood viscosity at high shear rate.

As we indicated in our introduction, Le Dévéhat [12] studied what he called "isolated obesity", i.e., obesity devoid of metabolic disturbances, and reported in this situation an increase in erythrocyte aggregation, a decrease in red blood cell deformability, an increase in plasma viscosity, and an increase in fibrinogen. He concluded that plasma proteins metabolism and thus RBC aggregation could be altered only because of weight excess by its own. Some years before, Jung [10] had already reported that body weight is associated with increased plasma viscosity. Later, this relationship has been largely and unanimously confirmed.

Whether there is a subgroup of obese patients who don't exhibit the usual metabolic disturbances associated with obesity is not a new finding. It was for example well known that moderate lower body obesity in women exhibited a metabolic profile that was quite the opposite of the so-called 'metabolic syndrome' or 'insulin resistance syndrome'. In the late nineties we reported that insulin sensitivity was higher in moderately overweight women with predominantly lower body fat [15]. This finding was consistent with the reports of a lower cardiovascular risk and a lower risk of becoming diabetic in patients exhibiting this variety of obesity $[8,18]$. On the whole, it remains well established that an upper body/visceral fat distribution in obesity is closely linked with metabolic complications, whereas increased lower body fat is independently predictive of reduced cardiovascular risk [9]. 


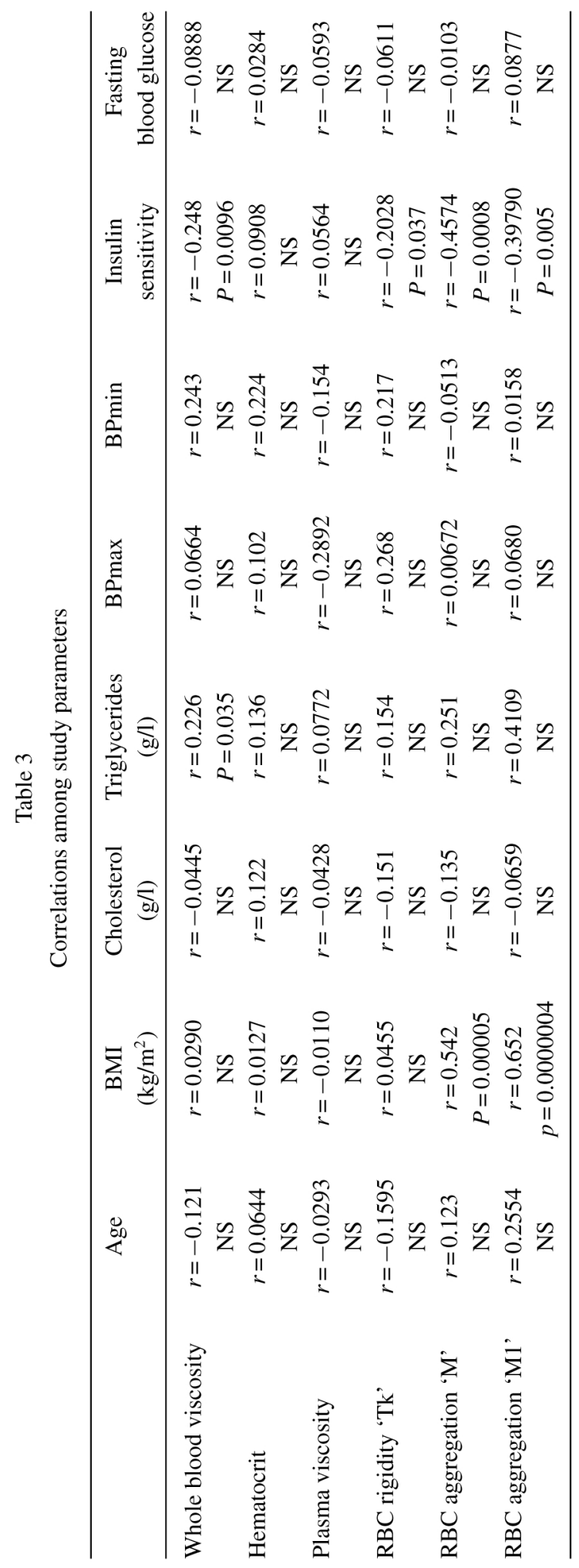


On the whole MHO is not associated with alterations of blood viscosity at high shear rate, but exhibits a slight increase in RBC aggregability. In other terms increased RBC aggregability ' $M$ ' seems to be more related to fatness by its own than to the occurrence of metabolic abnormalities.

\section{Conclusions}

These data are consistent with the assumptions that 1) MHO is on the whole a "hemorheologically healthy" situation, and 2) that RBC aggregability is proportional to fatness even in "healthy" conditions, as already observed in samples of normal weight athletes.

\section{Acknowledgments}

The authors affirm that they have no disclosure of interest concerning the issue investigated in this paper. This study was presented as oral communication at the 17th Conference of the European Society for Clinical Hemorheology and Microcirculation (ESCHM) 6-9 July, 2013, Pécs, Hungary.

\section{References}

[1] J.F. Brun, E. Varlet-Marie, E. Raynaud de Mauverger and J. Mercier, Both overall adiposity and abdominal adiposity increase blood viscosity by separate mechanisms, Clin Hemorheol Microcirc 48 (2011), 257-263.

[2] J.F. Brun, M. Guiraudou, C. Mardemootoo, A. Traoré, I. Raingeard, A. Chalançon and A. Avignon, Validation de la mesure segmentaire de la composition corporelle en comparaison avec la DEXA: Intérêt de la mesure de la masse grasse tronculaire, Science \& Sports 28 (2013), 158-162.

[3] L. Dintenfass, Blood viscosity, Hyperviscosity \& Hyperviscosaemia, Melbourne, MTP press, 1985, 482.

[4] J. Doffin, R. Perrault and G. Garnaud, Blood viscosity measurements in both extensional and shear flow by a falling ball viscometer, Biorheology 21(Suppl 1) (1984), 89-93.

[5] M. Donner, M. Siadat and J.F. Stoltz, Erythrocyte aggregation: Approach by light scattering determination, Biorheology 25 (1998), 367-375.

[6] M. Hamer and E. Stamatakis, Metabolically healthy obesity and risk of all-cause and cardiovascular disease mortality, JCEM 97 (2012), 2482-2488.

[7] M.Y. Jaffrin and H. Morel, Body fluid volumes measurements by impedance: A review of bioimpedance spectroscopy (BIS) and bioimpedance analysis (BIA) methods, Med Eng Phys 30(10) (2008), 1257-1269.

[8] M.D. Jensen, M.W. Haymond, R.A. Rizza, P.E. Cryer and J.M. Miles, Influence of body fat distribution on free fatty acid metabolism in obesity, J Clin Invest 83(4) (1989), 1168-1173.

[9] M.D. Jensen, Role of body fat distribution and the metabolic complications of obesity, J Clin Endocrinol Metab 93(11 Suppl 1) (2008), S57-S63.

[10] F. Jung, H.G. Roggenkamp, E.B. Ringelstein, G. Leipnitz, R. Schneider, H. Kiesewetter and H. Zeller, Effect of sex, age, body weight, and smoking on plasma viscosity, Klin Wochenschr 64 (1986), 1076-1081.

[11] A.D. Karelis, Metabolically healthy but obese individuals, Lancet 372 (2008), 1281-1283.

[12] C. Le Devehat, T. Khodabandehlou and M. Dougny, Hemorheological parameters in isolated obesity, Diabete Metab 18(1) (1992), 43-47.

[13] F.B. Ortega, D.C. Lee, P.T. Katzmarzyk, J.R. Ruiz, X. Sui, T.S. Church and S.N. Blair, The intriguing metabolically healthy but obese phenotype: Cardiovascular prognosis and role of fitness, Eur Heart J 34(5) (2012), 389-397.

[14] D. Quemada, Rheology of concentrated disperse systems II. A model of non Newtonian shear viscosity in steady flows, Rheol Acta 17 (1978), 632-642.

[15] E. Raynaud, A. Pérez-Martin, J.F. Brun, C. Fédou and J. Mercier, Insulin sensitivity measured with the minimal model is higher in moderately overweight women with predominantly lower body fat, Horm Metab Res 31 (1999), $415-417$. 
[16] H. Schmid-Schönbein, E. Volger and H.J. Klose, Microrheology and light transmission of blood III: The velocity of red cell aggregate formation, Pflügers Arch 254 (1975), 299-317.

[17] E.A. Sims, Are there persons who are obese, but metabolically healthy? Metabolism 50(12) (2001), $1499-1504$.

[18] R.B. Terry, M.L. Stefanick, W.L. Haskell and P.D. Wood, Contributions of regional adipose tissue depots to plasma lipoprotein concentrations in overweight men and women: Possible protective effects of thigh fat, Metabolism 40(7) (1991), 733-740.

[19] A. Vayá, R. Alis, D. Bautista and B. Laiz, Are abdominal obesity and body mass index independent predictors of hemorheological parameters? Clin Hemorheol Microcirc 56(1) (2014), 83-85. 